\title{
A Field Assessment on Natural Ventilation and Thermal Comfort of Historical District-A Case of the Wugoushui Settlement in Taiwan
}

\author{
Yu-Chieh $\mathrm{Chu}^{1}$, Min-Fu Hsu ${ }^{1}$ and Chun-Ming $\mathrm{Hsieh}^{2}$ \\ 1. Department of Architecture, Nation Cheng-Kung University, Tainan City 701, Taiwan (R.O.C.) \\ 2. Department of Urban Planning, Research Center of Green Building and New Energy, Tongji University, Shanghai 200092, China
}

\begin{abstract}
Due to the urban and town development, it is common to see historical buildings and new buildings intermingled with one and another inside historical regions in Taiwan. With the increase of new buildings, natural ventilation becomes harder, which leads to the impact on the preservation of historical building and the reduction of thermal comfort for residents. Besides, problems of new buildings' construction and design affect the developments of cities and towns in historical district, which has existed for hundreds of years. The Wugoushui Settlement is located in Pingtung County, the southernmost part of Taiwan, and its hot season of a year is pretty long and belongs to warm and humid tropical climate. In 2008, the Pingtung County Government officially registered and announced Wugoushui as traditional settlement and meanwhile, provided the maintenance and preservation for buildings in this region on government subsidies. This paper is based on one-year-long field experiments of Wugoushui Settlement. Residents in Wugoushui Settlement continue constructing new buildings near by the traditional buildings. With the fact that constructions of new buildings result in huge impact on the circumstances of natural ventilation and thermal comfort, which have been for hundreds of years, the simple weather station is set up to collect the data of local microclimate. In addition, four representative traditional architectures were selected to be measured their indoor and outdoor temperature, humidity, wind speed, wind direction and thermal radiation both in winter (December to February) and in summer (May to September). The measurement time of each building is one week and every data record is kept every minute. Besides, residents were asked to fill out the comfort survey. Based on these data, the distributions of indoor and outdoor thermal environment as well as the thermal comfort of living space under the condition of the natural ventilation are assessed. Finally, focused on the indoor living space of historical districts in southern Taiwan, there are two main suggestions given in the essay: first, a provisional comfort zone in summer is planned and proposed; second, the preliminary suggestions for the design and norms of new buildings in historical district are provided.
\end{abstract}

Key words: Historical district, historical settlement, natural ventilation, thermal comfort, physical environment measurement, PMV.

\section{Introduction}

Due to ongoing development in towns or cities within Taiwan's historical areas, many of them see a chaotic mix of historical buildings and modern architectural structures. Some buildings of preservation value have become the focus of government conservancy efforts. Among these, the "settlement" preservation category faces dire straits; it is not possible to manage and control the environment

Corresponding author: Yu-Chieh Chu, Ph.D. student, research fields: Taiwan traditional architecture and settlement, environment simulation (computational fluid dynamics, CFD), climate and cultural heritage conservation, etc. as well as the construction of new buildings because current laws are lax. As temperatures climb continuously, unlike modern buildings, historic buildings are unable to change their facades or configurations to improve the level of living comfort. With many indoor environments lacking air-conditioning, the comfort level of residents has become the key to the settlement's sustainable development.

In his study, Ahmed [1] found that improvements in the outdoor thermal environment could lead to enhancing the indoor thermal environment, relieving the stress of indoor thermal control. Gagge [2] 
presented experimental results that show the impact of wind speed on the thermal comfort index. Raising indoor wind speed from $0 \mathrm{~m} / \mathrm{s}$ to $0.72 \mathrm{~m} / \mathrm{s}$ greatly reduces the PMV value. From these research data, it is known that outdoor thermal environment can affect indoor thermal environment and that the change in wind speed has significant impact on the thermal comfort levels.

Measured results for thermal comfort from various countries [3, 4] show that the long-term weather patterns of each country affects thermal preference. Results from other studies also point out those who use air-conditioning at a lesser degree and are able to adapt to an environment with higher temperatures prefer a higher thermal comfort level [5]. Fanger [6] first established a set of theoretical models to explain the relationship between indoor thermal comfort level and energy balance, which he eventually developed into the PMV predicts. This indicator categorized subjective sensations of warmth and coldness into seven levels from +3 to -3 : hot, warm, slightly warm, neutral, slightly cool, cool, and cold. It received recognition from the International Standard Organization (ISO); ISO7730 is designated as the thermal assessment method [7]. However, in the same space, despite similarities in the amount of activity and clothing, there are small numbers of people who do not feel comfortable. Consequently, in consideration of subjective individual differences, PPD is also often used to gauge the level of dissatisfaction that the human body has with the environment. ISO7730 recommends that at PPD < $10 \%,-0.5<\mathrm{PMV}<0.5,90 \%$ of people are satisfied; this zone is considered the comfort zone for living. When PMV $=0$, it is considered thermally neutral sensation. When PMV $=0$, it is considered thermally neutral sensation. The subjects for the initial PMV survey came from temperate countries. Fanger [8] proposed modifying the coefficient to between 0.5 and 1 for countries with warm climates. According to the measured results of thermal comfort for each country, long-term climatic conditions affect the heat endurance capabilities of the residents. Consequently, this study uses the thermal comfort zone after PMV has been extended, designating PMV $<-1$ and $>+1$ as unsatisfactory, $-1<$ PMV $<+1$ as satisfactory, which is the range within which $80 \%$ of people feel satisfied to assess level of indoor thermal comfort.

To resolve the issue of discomfort in living in historic buildings, residents usually build new structures near the historic ones they originally lived in. This has resulted in the increase in new building structures, with the settlement seeing one-story historical buildings alongside 3-5 story new structures. The main purpose of this study is to understand the indoor and outdoor thermal environmental situation in historic settlements and improve the indoor thermal comfort. As a result, it conducts simultaneous indoor and outdoor measurements under natural ventilation to find the factors affecting the thermal environment of historic buildings, assess the impact of outdoor wind speed on indoor wind speed, and try to lower PMV values through changes in indoor and outdoor wind speeds, raising the thermal comfort levels of the historic buildings' indoor environment.

\section{Materials and Methods}

\subsection{Study Area and Meteorological Data}

Wugoushui Settlement is located in Pingtung County, the southernmost part of Taiwan; it has the warm humid weather of a tropical climate. Because it has many unique features, many historical buildings are preserved within this settlement. It was registered as a legal settlement; preservation zone is about 5.2 $\mathrm{km}^{2}$. There are about 500 longtime residents in Wugoushui Settlement, with the majority in their 60 's, followed closely with children below 12; most of the young people have left their hometown to work. Consequently, the age group of the residents makes for weak adjustment to the hot environment. The closest meteorological station to Wugoushui Settlement is the Chaozhou station. Analyzing the 


\section{A Field Assessment on Natural Ventilation and Thermal Comfort of Historical District-A Case of the Wugoushui Settlement in Taiwan}

10-year (2002-2011) weather data (Figs. 1 and 2) from the Chaozhou station, it was found that the area does not experience significant seasonal changes; there are two major seasons: hot and cool, with the former running from May to September and the latter running from December to February. The hottest time of the day is noontime, between 11:00 and 15:00; this is the time period when thermal comfort needs to be improved.

\subsection{Field Experiment}

To measure the natural ventilation and indoor thermal comfort level of the Wugoushui Settlement, the study set up a yearlong (02/2014-02/2015) fixed observation station in its periphery. The instruments were set up at a height of $11.3 \mathrm{~m}$ from the ground, collecting data on the local temperature, humidity, wind speed, wind direction, and insolation; a piece of data was automatically recorded every five minutes. In addition, actual observations were conducted in accordance with the hot season $(2 / 02 / 2015-28 / 02 / 2015)$ and the cool season (26/08/2014-30/09/2014). Four case studies within the settlement were chosen, where a total of eight indoor and outdoor observation stations measure and collect data on temperature, humidity, wind speed, wind direction, wet bulb temperature, and black bulb temperature. Measurement length of time is one week;

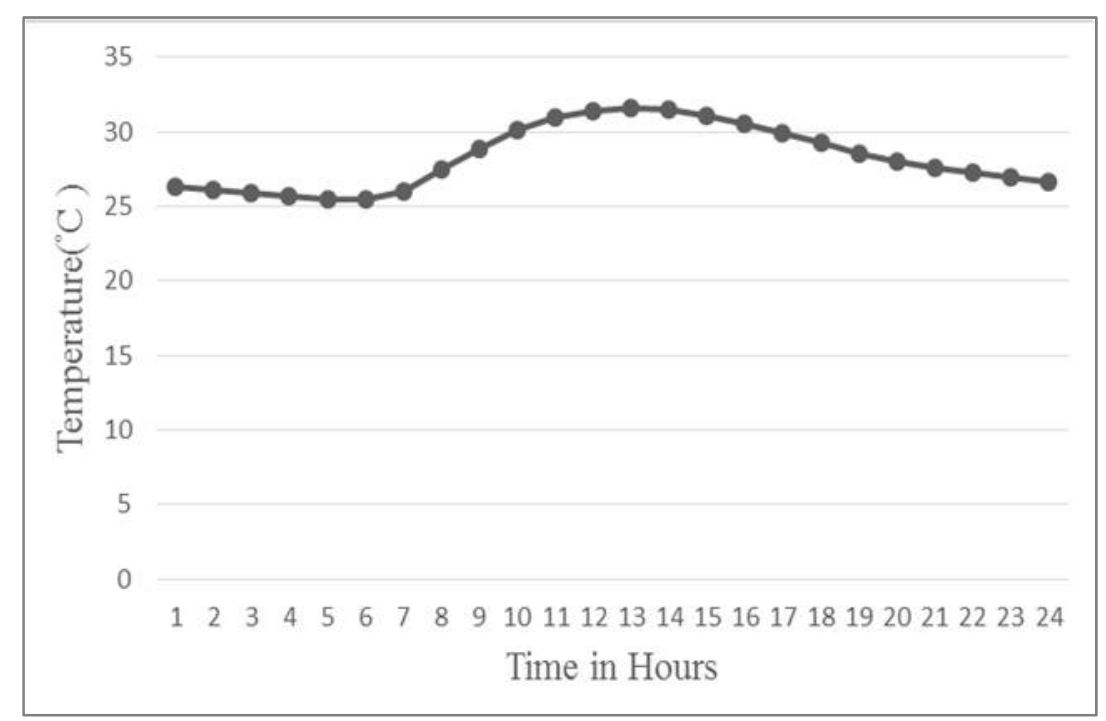

Fig. 1 Average temperature during hot season (meteorological station, 2002-2011).

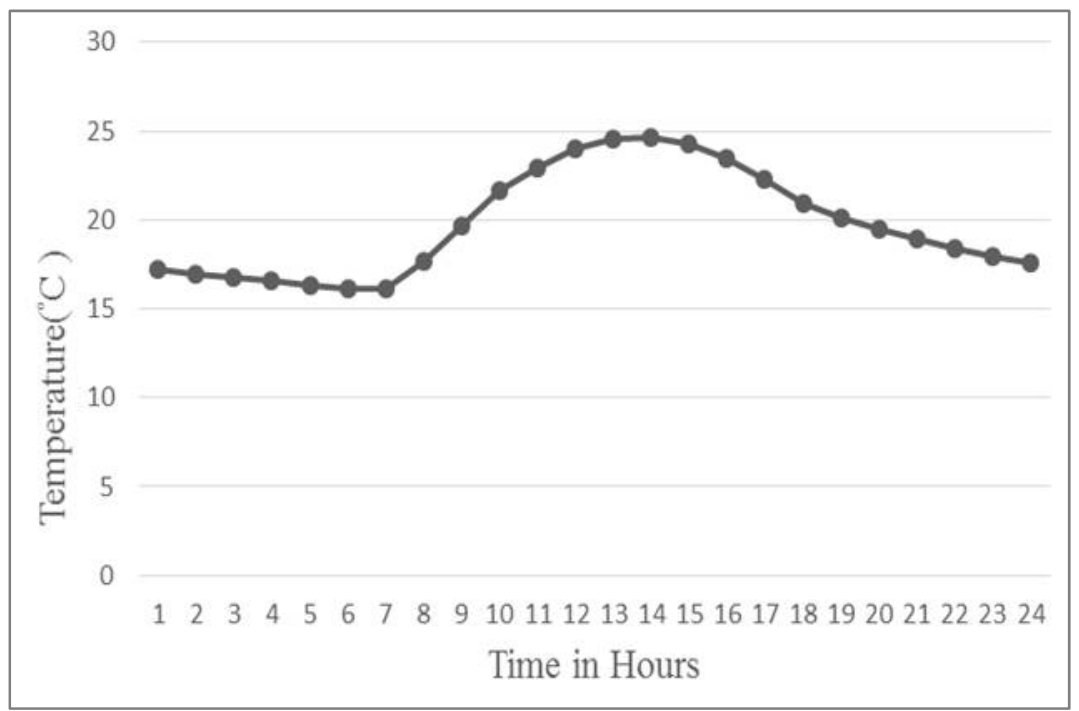

Fig. 2 Average temperature during cool season (meteorological station, 2002-2011). 
a piece of data was automatically recorded every minute. Because the average zone of human breathing is between 0.5 and $1.5 \mathrm{~m}$, the instruments were set up at a height of $1.5 \mathrm{~m}$. Instrument precision meets the standards of ISO 7726 for measurement instruments [9]. The instruments used in the study and their accuracy levels are shown in Table 1.

In addition, in terms of indoor and outdoor instrument measurement periods, there were three time periods for residents of historic buildings: morning, noon, and afternoon; the study conducted a day of questionnaire surveys and interviews. It used the interview survey method. From the process, the study was able to obtain not only the basic information of the residents who move around the space, but also the amount of activity levels, clothing insulation worn by subjects, as well as subjective feelings regarding thermal sensation, thermal acceptance, and thermal comfort. In the case studies chosen by this study, actual residents of each case are between 1 and 4 people; as a result, the number of questionnaires was very limited. There are a total of 57 questionnaires, 33 for hot season and 24 for cool season.

In accordance with the thermal sensation scale of the PMV, the thermal comfort questionnaire categorizes the thermal sensations of the interviewees into cold (-3), cold (-2), slightly cool (-1), neutral (0), slightly warm (1), warm (2), and hot (3). According to levels of thermal acceptability, the interviewees were categorized into two conditions: acceptable (1) and unacceptable (2). The study calculates the mean radiant temperature of the environment based on the survey information as well as measurement instrument data, using the calculation method (formula 1) of natural convention from ISO 7726 (1895). Then the study calculates the PMV value using the RayMan calculation software. Furthermore, we use $-1<$ PMV $<+1$ to draw the comfort zone, and complementing the information on comfort level and acceptable levels from the questionnaires, find the comfortable temperatures acceptable to the residents.

Table 1 Instruments used and levels of accuracy.

\begin{tabular}{|l|l|l|}
\hline Elements & Device & Accuracy \\
\hline $\begin{array}{l}\text { Air temperature } \\
\text { relative humidity }\end{array}$ & $\begin{array}{l}\text { YOUNG-41382VC } \\
\text { YOUNG-41003 }\end{array}$ & $\begin{array}{l} \pm 0.3^{\circ} \mathrm{C} \\
\pm 2 \%\end{array}$ \\
\hline Wind speed \& direction & YOUNG-05103 & $\pm 0.3 \mathrm{~m} / \mathrm{s}$ \\
& YOUNG-85000 & $\pm 0.1 \mathrm{~m} / \mathrm{s}$ \\
\hline $\begin{array}{l}\text { Black bulb temperature wet bulb temperature } \\
\text { Dry bulb temperature } \\
\text { Relative humidity }\end{array}$ & & $\pm 0.5^{\circ} \mathrm{C}$ \\
$\pm 0.5^{\circ} \mathrm{C}$ \\
$\pm 0.5^{\circ} \mathrm{C}$ \\
$\pm 3 \%$
\end{tabular}

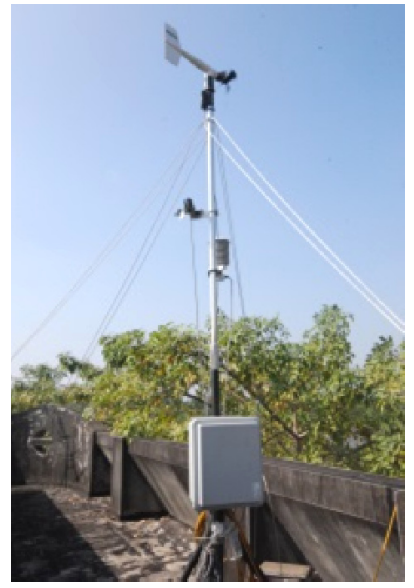

Fixed observation station

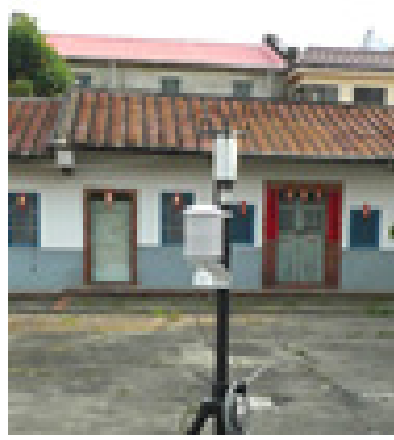

Outdoor observation station

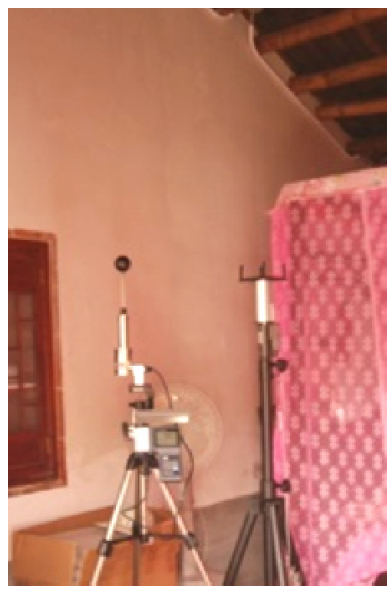

Indoor observation station 


\section{Wugoushui Settlement in Taiwan}

$$
\begin{gathered}
\operatorname{tmrt}=\left[\left(t_{\mathrm{g}}+273\right)^{4}+0.4 \times 10^{8}\left|t_{\mathrm{g}}-t_{\mathrm{a}}\right|^{\frac{1}{4}}\right. \\
\left.\times\left(t_{\mathrm{g}}-t_{\mathrm{a}}\right)\right]^{1 / 4}-273
\end{gathered}
$$

$t_{\mathrm{g}}$ : black bulb temperature $\left({ }^{\circ} \mathrm{C}\right)$;

$t_{\mathrm{a}}$ : dry bulb temperature $\left({ }^{\circ} \mathrm{C}\right)$.

\section{Results and Discussion}

\subsection{Data Verification}

The number of instruments limits simultaneous indoor and outdoor observation. Measuring four case studies in two different time periods, the study needed to have two sets of instruments for measuring temperature, humidity, wind speed, and wind direction set up indoor and outdoor to conduct simultaneous measurement. Furthermore, the WBGT-101 was set up indoor to measure black bulb and wet bulb temperatures. To confirm that the research data of the four case studies can be compared and analyzed against each other, the temperature and humidity data from the fixed observation stations set up for the four case studies during the two time periods are used. First, the study converts time series data to conduct model fitting for the harmonic model. Then, residual analysis on the harmonic model is conducted before drawing the control line using -3 to +3 standard deviation as the standard; the control line reduces probability of error to below 0.0027 . In a situation where in the volume of data does not exceed 10,000 pieces, whether the residual value falls within the standard deviation range of $-3 /+3$, it can be determined whether the time periods belong to the same climate zone on which to conduct comparative analysis.

In the control chart drawn using the residual values of temperature and humidity during hot season, values primarily falls within the control chart of the $-3 /+3$ standard deviation range. Among these, one point was lower than the control line; this piece of data, which was later not used, was affected by Typhoon Phoenix. Temperature values of the winter season also fall within the control chart of the standard deviation range of $-3 /+3$; during this season, most of the humidity values fall within the same standard deviation range. Among these, three points were lower than the control line; these pieces of data, were later not used due to the effects of heavy rains. In summary, after verification, the study determines that the climatic conditions of the four case studies in the observation period belong to the same zone, which means that the observation data can be comparatively analyzed.

\subsection{Case Study Selections and Physical Environment Measurement}

For security and to prevent theft, openings of the historical buildings in the Wugoushui Settlement to the outside world are small, with the main body of the building horseshoe or rectangular-shaped. The main body is an inner open space covered from the outside; the main opening of this inner space faces this open space. In this type of architecture, opening and the direction it faces affect the thermal comfort level of residents living in historical buildings. The study chooses the two types of architecture most historical buildings in the settlement belong to as research cases (Table 2). All of the case studies have 3-4 windows and one door, all using natural ventilation; the walls are made of bricks; roof truss is wooden, covered with red slates. The windows of Case A and Case $\mathrm{C}$ do not close; windows of Case C and Case D can be opened and closed at will. Case A and Case B belong to the same building type, with the direction of the opening at 90 degree perpendicular, while the building types of Case C and Case D are different, but direction of the openings is the same.

Analyzing the fixed observation stations, as well as the average outdoor and indoor temperature, humidity, and wind speed of Cases A, B, C, and D in a week (Figs. 3 and 4). Fixed observation stations provide the primary wind direction and wind speed; because the wind field of the ground is very complex, it is easily 
Table 2 Basic information of case studies.

\begin{tabular}{|l|l|l|l|l|}
\hline Actual measurement points & $\begin{array}{l}\text { Case A } \\
\text { Liushizongci }\end{array}$ & $\begin{array}{l}\text { Case B } \\
\text { Guangyuizhutang }\end{array}$ & $\begin{array}{l}\text { Case C } \\
\text { Wanchengzhutang }\end{array}$ & $\begin{array}{l}\text { Case D } \\
\text { Hexinghuofang }\end{array}$ \\
\hline Direction of the building's primary opening & W-E & N-S & NNE-SSSW & NNE-SSSW \\
\hline Measurement of the direction of the space's opening & N-S & W-E & ESE-WNW & ESE-WNW \\
\hline Building plan & & & \\
\hline $\begin{array}{l}\text { N.B. Outdoor observation station is marked red points; indoor observation station is marked black points. The direction of building's } \\
\text { opening is according to the direction the door faces; the direction it rests on is the sitting direction. }\end{array}$
\end{tabular}

affected by interference from buildings or plant life. Comparing the average wind speed and direction of the outdoor measurement stations, it is seen that they are very different from those of the fixed observation stations. Case D structure is enclosed; thus, indoors and outdoors wind speed is lowest. For Case A and Case C, because their windows cannot be closed, indoors wind speed for hot and winter seasons are higher and temperatures are lower. The positions of Case C and Case D are closer; building type is different and direction of measured space opening is similar. However, because windows of Case D can be closed, indoors wind is stronger in Case $\mathrm{C}$ than that in Case D.

The outdoor wind speed of the case studies is primarily affected by their building type and secondarily by the direction they face. Indoor wind speed is primarily influenced by the presence or absence of openings and secondarily by the direction of openings. Analyzing the actual measurement data, the study finds that the building opening, building type, building orientation and position, in that order, are the factors affecting the indoor comfort levels of historical buildings.

\subsection{Analysis of Thermal Comfort}

The study uses actual measurement data as well as survey questionnaires on indoor thermal comfort level to analyze the neutral temperature as well as the difference in comfort zone. Both start with the temperature acceptable to $80 \%$ of the people; when both PMV and TSV values are between -1 and +1 , this is considered the comfort zone. When PMV $=0$, neutral temperature during the hot season is $25.9^{\circ} \mathrm{C}$; neutral temperature during the cold season is $22.5^{\circ} \mathrm{C}$. The comfort zone $(1<\mathrm{PMV}<+1)$ during the hot season is between 27.93 and $30.38^{\circ} \mathrm{C}$, accounting for $32.43 \%$ response rate; the comfort zone during the cold season is between 20.36 and $24.59{ }^{\circ} \mathrm{C}$, accounting for $75 \%$ response rate. When $\mathrm{TSV}=0$, neutral temperature during the hot season is $28.64{ }^{\circ} \mathrm{C}$; neutral temperature during the cold season is $22.3^{\circ} \mathrm{C}$. The comfort zone $(1<\mathrm{TSV}<+1)$ during the hot season is between 27.93 and $31{ }^{\circ} \mathrm{C}$, accounting for $75.76 \%$ of the respondents falls within this range; the comfort zone during the cold season is between 16.51 and $26.97{ }^{\circ} \mathrm{C}$, accounting for $91.67 \%$ of the respondents falls within this range. Analyzing the degree of thermal acceptability, during the hot season for all time periods is $81.82 \%$, while that during the cold season is $100 \%$. In the PMV-PPD curve (Fig. 5), where PMV is between 1 and +1 and PPD is at $20 \%$, $80 \%$ of the people will feel comfortable.

The number of people in the comfort zone for PMV values of the hot season is morning $>$ noon $=$ afternoon, while that for the cold season is morning $=$ afternoon $>$ noon. In the mornings during the hot season, most people voted for TSV $=0$; the number of people in the comfort zones of the hot season for all time periods is morning $>$ afternoon $>$ noon, while for the cold season, most people voted for TSV $=0$ and the number of people in the comfort zone is afternoon $>$ morning $>$ noon. In terms of the voting values of PMV and TSV on each time period, the estimates for both seasons are 

Wugoushui Settlement in Taiwan

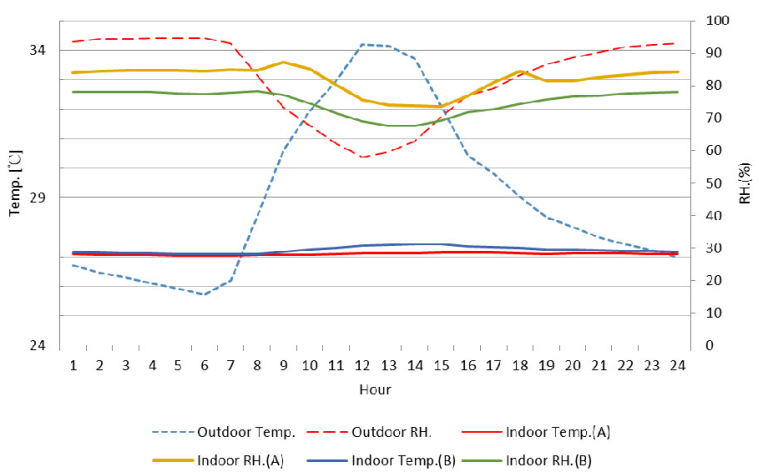

Case A and B in hot season

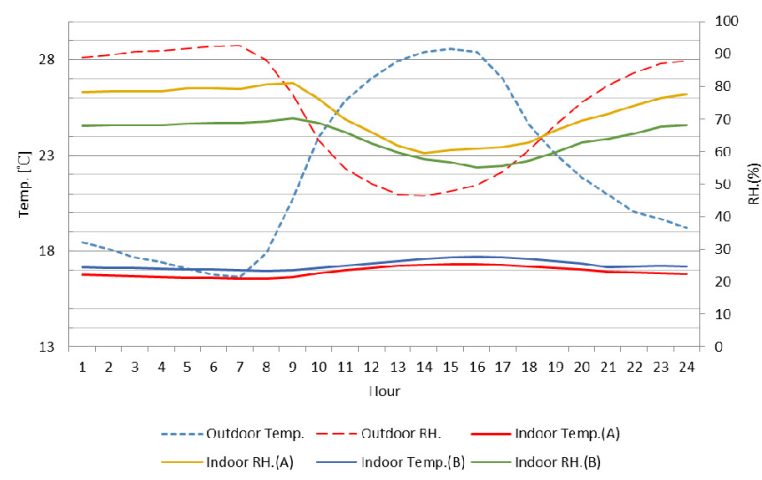

Case A and B in cold season

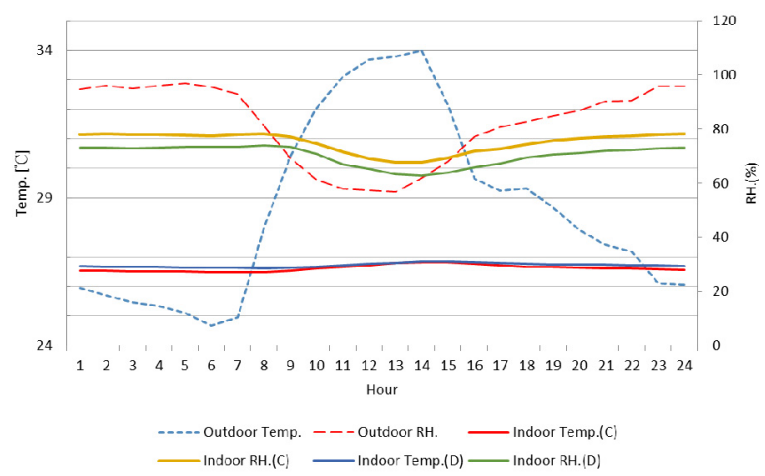

Case $\mathrm{C}$ and $\mathrm{D}$ in hot season
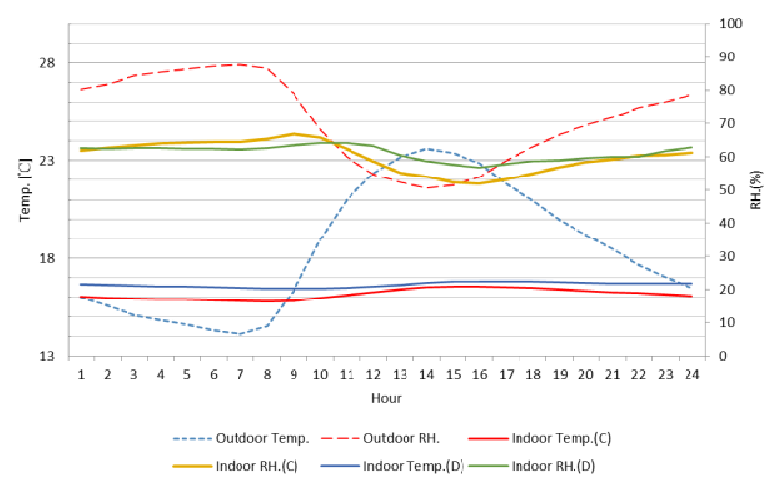

Case $\mathrm{C}$ and $\mathrm{D}$ in cold season

Fig. 3 Average indoor and outdoor humidity data of observed local historical buildings (2014-2015).

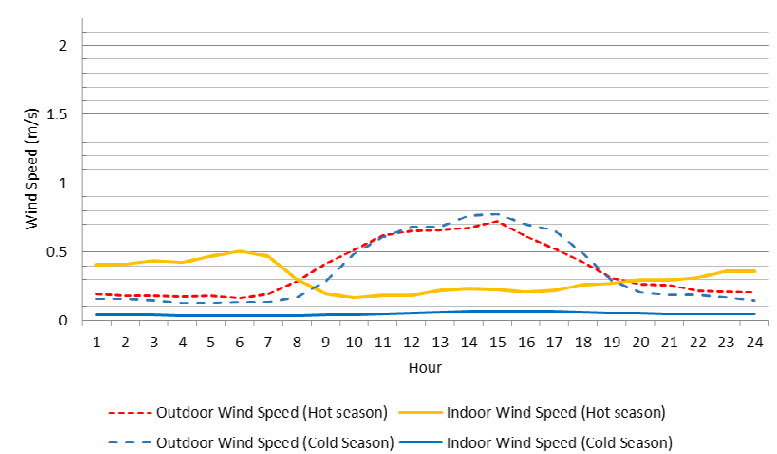

Case A

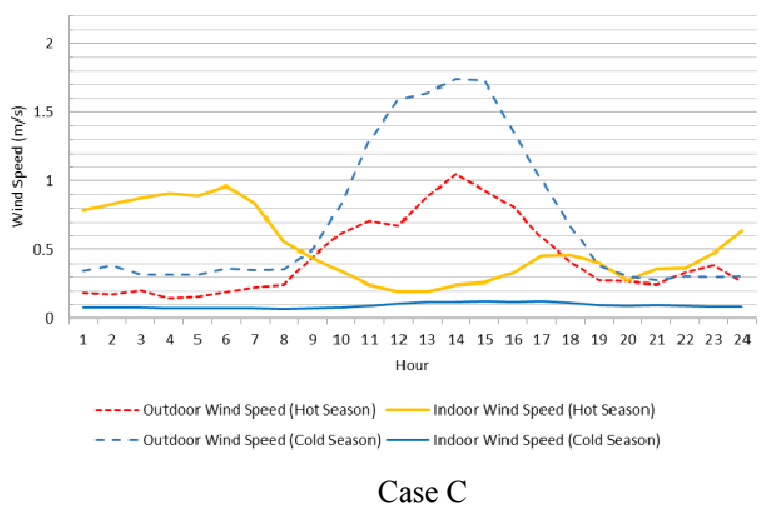

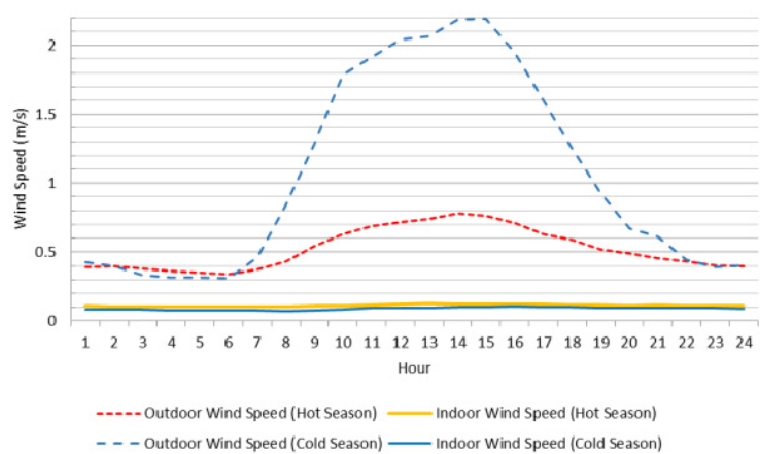

Case B

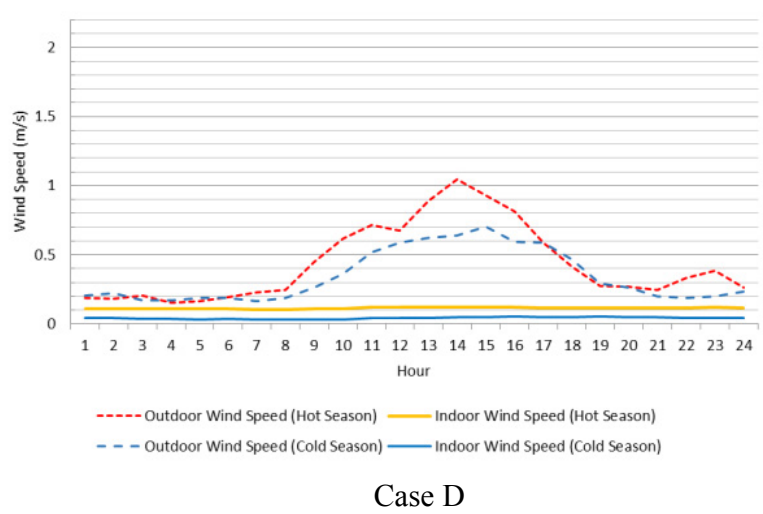

Fig. 4 Average indoor and outdoor wind speed data of observed local historical buildings (2014-2015). 


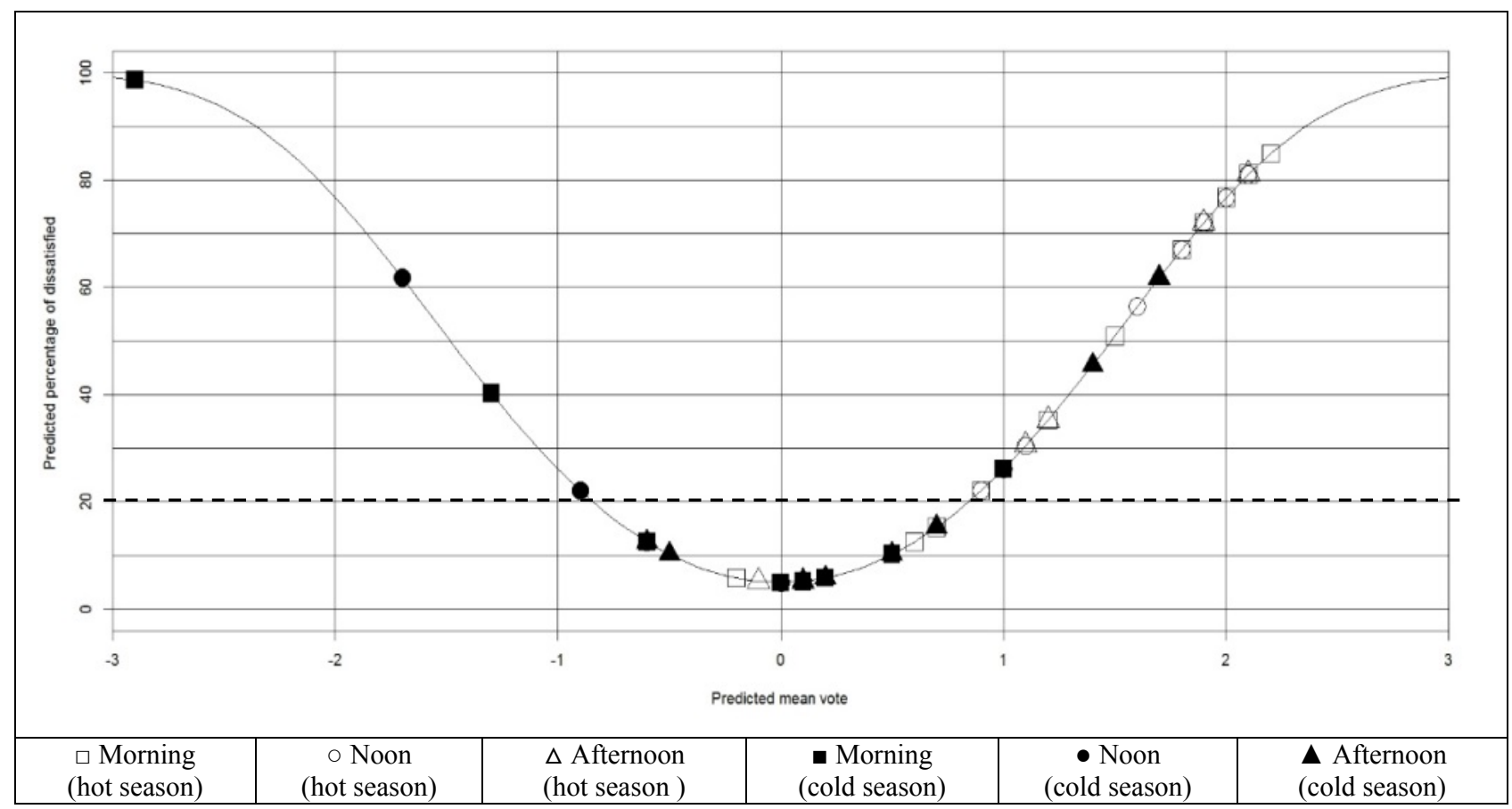

Fig. 5 PMV-PPD curve for morning, noon, and afternoon time periods in hot and cold seasons.

very similar. The level of comfort during the morning period of the hot season is the most ideal and the noontime period is the least ideal, while during the cold season the levels of comfort for morning and afternoon are the most ideal, while that for noontime is the least ideal. The voting ratio for noontime during the cold season is higher than that during the hot season.

The comfort zone for hot season is $27.93 \sim 29.57^{\circ} \mathrm{C}$ and the scope of comfort is concentrated in the morning; the scope of comfort derived from PMV-PPD is closer to that derived from PMV. The comfort zone for cold season is $20.36 \sim 20.59{ }^{\circ} \mathrm{C}$ and the scope of comfort is largely concentrated in the morning and the afternoon; the scope is lower than the one derived from PMV.

\subsection{Wind Speed and PMV}

Because preservation laws impose numerous limitations on historical buildings, it is difficult to make major changes to their facades or configuration in terms of improving natural ventilation to enhance the level of indoor thermal comfort. Although making changes on traditional building materials is another way to make improvements, this is not within the scope of the study. The study uses the increased wind speed method to lower the PMV value of indoor environment, improving the indoor thermal comfort.

Based on the abovementioned analysis, noontime during the hot season is the time period that needs the most improvement. Analyzing the relationship between the outdoor and indoor wind speed and PMV values for noontime during the hot season, the study presents the wind speed value needed to improve this time period. First, the study uses linear regression to look at the outdoor and indoor wind speed by the presence and absence of openings; it finds that the two of the windows of the cases do not close are very much interrelated, with a relevant coefficient of $R^{2}=$ 0.9381. Moreover, in analyzing the measurement points outside of the indoor comfort zone of noontime during the hot season (PMV $<-1$ and PMV $>+1$ ), indoor wind speed can be strengthened to within the $0.3-5.6 \mathrm{~m} / \mathrm{s}$ range, average wind speed increases to $3.42 \mathrm{~m} / \mathrm{s}$, successfully reducing PMV values to within the comfort zone. This, in turn, raises the level of comfort of the indoor environment of the hottest time period. 


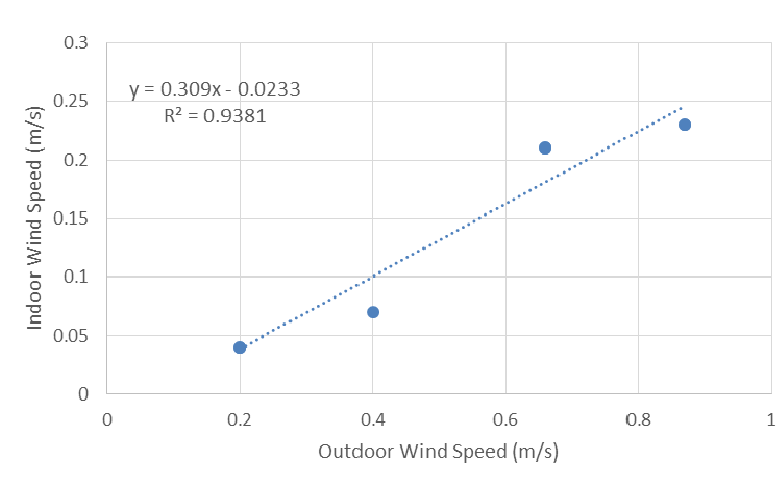

The windows of the cases do not close

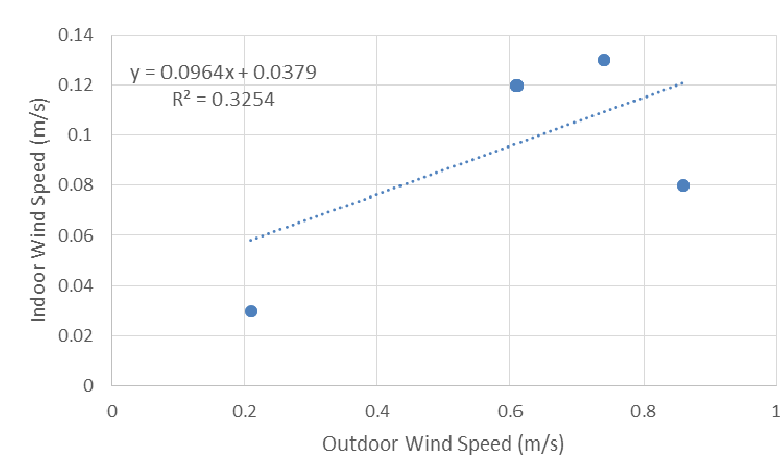

Windows of the cases can be opened and closed at will

Fig. 6 Relationship between indoor and outdoor wind speeds of noontimes during hot season and mornings during cold season.

\section{Conclusions}

(1) The study finds that factors influencing the level of indoor thermal comfort in historical buildings, in the order of level of influence, are the building opening, building type, and building orientation and position. This is why, in light of historical buildings unable to change their facades and configuration, and changing building materials is not a consideration, what is relevant to building openings is that the major factor of indoor thermal comfort is wind speed.

(2) Thermal neutral temperature of the PMV value of the hot season is low; there is only a $0.2{ }^{\circ} \mathrm{C}$ difference between the thermal neutral temperatures of the PMV and TSV values of the cold season. The thermal neutral temperatures of the PMV and TSV values of the hot and cold seasons are similar to each other. However, the ratio of hot environment of hot season falling within the comfort zone is low $(32.43 \%)$; the figure is higher during the cold season (75\%). Survey results show that ratio for choosing thermal neutral temperature during the hot season is about $15.15 \%$, while the ratio for making the same choice during the cold season is $56.52 \%$. This means that humidity levels of hot and cold seasons in the locality are exceedingly high; even if the hot environment is within the comfort zone during the cold season, close to one-half of the residents still feel uncomfortable.

(3) In the thermal sensation analysis of the residents,
PMV overestimated the thermal sensation of the residents. The thermal acceptability during the hot season is $81.82 \%$, while that of the cold season is $100 \%$. This shows that when interviewees experienced slight environmental discomfort, they are still able to accept the environment; this means the residents have a certain tolerance for heat.

(4) Under specific temperature and humidity conditions, the wind does contribute to heat dispersion in the body as well as lowering body temperature. During the hottest time period of the hot season, average indoor wind speed increases to $3.42 \mathrm{~m} / \mathrm{s}$, effectively reducing PMV values within the comfort zone.

\section{References}

[1] Ahmed, K. S. 2003. "Comfort in Urban Spaces: Defining the Boundaries of Outdoor Thermal Comfort for the Tropical Urban Environments." Energy and Buildings 35 (1): 103-10.

[2] Gagge, A. P. 1967. "Comfort and Thermal Sensations and Associate Physiological Responses at Various Ambient Temperatures." Environmental Research 46 (7): 125-32.

[3] Mc Cartney, K. J., and Nicol, J. F. 2002. "Developing an Adaptive Control Algorithm for Europe." Energy and Buildings 34: 623-35.

[4] Nicol, J. F. 2004. "Adaptive Thermal Comfort Standards in the Hot-Humid Tropics." Energy and Buildings 36: 628-37.

[5] Feriadi, H. et al. 2002. "Redefining Appropriate Thermal Comfort Standard for Naturally Ventilated Buildings in Tropics (Singapore and Indonesia Perspective)." Monterey Proceedings of the Indoor Air, 110-5. 

Wugoushui Settlement in Taiwan

[6] Fanger, P. O. 1972. Thermal Comfort: Analysis and Applications in Environmental Engineering. Copenhagen: Danish Technical Press.

[7] CEN ISO 7730. 1994. Moderate Thermal Environments-Determination of the PMV and PPD Indices and Specification of the Conditions for Thermal Comfort, International Organization for Standardization,
Geneva.

[8] Fanger, P. O. 2002. "Extension of the PMV Model to Non-Air-Conditioned Buildings in Warm Climates." Energy and Buildings 34: 533-6.

[9] CEN ISO 7726. 1998. Thermal Environment-Instruments and Method for Measuring Physical Quantities, International Organization for Standardization, Geneva. 